Pemikiran Politik K.H Moenawar Chalil (1908-1961)| Fajar Tahmid Aqimuddin, Fajriudin, Dina Marliana

\title{
Pemikiran Politik K.H Moenawar Chalil (1908-1961)
}

\author{
Jafar Tahmid Aqimuddin, Fajriudin, Dina Marliana \\ Universitas Islam Negeri Sunan Gunung Djati \\ Fakultas Adab dan Humaniora \\ Email: japartahmid@gmail.com
}

\begin{abstract}
K.H. Moenawar Chalil is an important figure who is almost forgotten in Indonesian history. He is one of the Indonesian scholars who existed in his time. He has several famous works that he has written since becoming a member of the Sarekat Islam in 1925 at the age of 17 years. Some of his works have been published in articles, newspapers, and the biggest one is in a book that is until now widely known. The Complete Date of the Prophet Muhammad. It turned out that he not only published books on the history of the Prophet Muhammad, but other books such as religious themes, and also politics. This research aims to reconstruct the political thought of K.H. Moenawar Chalil in Indonesia which is contained in his work, both from articles, newspapers and books. The study used four stages, namely Heuritics, Criticism, Interpretation and Historiography.
\end{abstract}

Keywords :Political thinking, K,H. Moenawar Chalil, Cleric

\section{Pendahuluan}

Salah satu tokoh yang hampir terlupakan dalam pergulatan politik yang pernah terjadi di Indonesia ialah K.H. Moenawar Chalil. Saat ini, dalam dunia kepenulisan beliau selebihnya hanya terkenal dalam bidang sejarah dan keagamaan saja. Dalam bidang sejarah beliau terkenal dengan karya tulisnya yang dituangkan dalam buku Kelengkapan Tarikh Nabi Muhammad, dan dalam bidang keagamaan tertuang dalam buku Definisi dan Sendi Agama. Namun jika menelusuri sejarah K.H Moenawar Chalil, beliau merupakan sosok yang berperan besar dalam dunia perpolitikan di Indoensia.

Beliau dalam sejarahnya telah merefleksikan kehidupan dalam aktivitasnya yang diwujudkan oleh semangat pembaharuan dalam 
Pemikiran Politik K.H Moenawar Chalil (1908-1961)| Fajar Tahmid Aqimuddin, Fajriudin, Dina Marliana

agama dan terimplementasikan di beberapa institusi dalam kegiatannya. Beliau pernah bergabung dan terlibat dalam Majelis Syura, Majelis Tarjih dan Majelis Ulama yang telah menandakan kuatnya dalam berkomitmen terhadap usaha-usaha pembaruan melalui majelis ini yang mampu mengembangkan, menyebarkan dan menjaga prinsp-prinsip yang dimilikinya.

Dalam kancah perpolitikannya beliau berkontribusi untuk menjadi Departemen Agama yang dimulai pada tahun 1942. Di sinilah beliau memikiran bagaimana peran ulama menjadi berfungsi dengan baik dalam negara Indonesia terhadap umatnya. Pada tahun 1951 Departemen Agama menyelenggarakan konferensi para ualama di Jakarta yang pertama. Di dalam konferensi tersebut beliau merekomendasikan bahwa pertemuan para ulama itu untuk dilanjutkan dengan memperluas menjadi sebuah lembaga yang bernama Dar alIfta', yakni lembaga dalam bidang keagamaan dengan mandat secara penuh untuk mengeluarkan fatwa-fatwa kepada umat di Indonesia.

K.H. Moeawar Chalil meskipun seorang ulama, beliau juga diakui kepopulerannya menjadi bagian 10 pengarang yang terkenal pada masanya. Pada tahun 1957 Himpunan Pengarang Indonesia mendaftarkan beliau sebagai salah satu dari sepuluh pengarang terkenal, diantaranya yaitu Tamar Jaya, Hamka, Mohammad Natsir, Zaenal Abidin Ahmad, A. Hassan, Hasby Ash-Shiddieqy, H. Z. Arifin Abbas, Isa Anshary, dan Firdaus Ahmad Naqib ${ }^{1}$.

\section{Metode Penelitian}

Metode penelitian ialah suatu hal yang sangat penting untuk melakukan sebuah penelitian, karena pada prinsipnya, metode penelitian yaitu sebuah cara yang ilmiah untuk mendapatkan beberapa kumpulan data dengan suatu tujuan dan dengan diadakannya kegunaan tertentu. Metode penelitian merupakan salah satu upaya untuk mencari, kemudian mengembangkan, menguraikan dan mengevaluasi kebenaran

\footnotetext{
${ }^{1}$ Ida Khikmawati, "Telaah Metodelogis Pemikiran K.H. Moenawar Chalil Tentang Slogan Kembali Kepada Al-Qur'an (Studi Atas Buku Kembali Kepada Al-Qur'an dan As-Sunnah)" (UIN Sunan Kalijaga, 2020), 3
} 
Pemikiran Politik K.H Moenawar Chalil (1908-1961)| Fajar Tahmid Aqimuddin, Fajriudin, Dina Marliana

pengetahuan dengan prosedur yang ilmiah. Maka dari itu, langkahlangkah dalam mencapai suatu metode yang akan digunakan untuk meneliti suatu penelitian harus tepat dan akurat.

Untuk melakukan penelitian, hal yang pertama yang penulis lakukan sebelum melakukan penelitian ialah menggunakan metode penelitian sejarah yaitu heuristik, yaitu mencari sumber yang berkaitan dengan judul penelitian. Karna tanpa sumber, penelitian ini tidak akan menjadi suatu karya sejarah. Oleh karena itu, pada metode ini yang dilakukan adalah mencari dan mengumpulkan sumber yang berkaitan dengan judul penelitian.

Metode heuristik yakni mengumpulkan sumber-sumber primer dan sumber sekunder. Sumber primer didapatkan dari buku-buku lawas yang merupakan karya asli K.H. Moenawar Chalil dan beberapa majalah yang pernah dipublikasikan. Kemudian sumber sekunder yang merupakan pendukung atas keberlangsungan penelitian ini terdiri dari dokumen, buku, dan media digital lainnya.

Metode selanjutnya ialah tahap verifikasi, yaitu kritik terhadap sumber untuk melihat keaslian dan keabsahan sumber yang digunakan dalam sebuah penelitian. Kemudian metode selanjutnya ialah melaukan tahap interpretasi, yakni menganalisis kumpulan sumber yang telah didapatkan menjadi sebuah uraian sejarah untuk dikelompokkan kemudian ditafsirkan agar sesuai dengan judul penelitian. Penulis mencoba untuk memberikan beberapa interprestasi pada sebuah judul yang hendak dijadikan objek penelitian, yaitu Pemikiran Politik K.H. Moenawar Chalil.

Lalu metode yang terakhir ialah tahap historiografi, yakni menyampaikan atau membangun ulang hasil dengan merekonsturksi kisah secara imajinatif seobjektif mungkin dari sumber sejarah yang telah dikumpulkan, dianalisis dan diinterpretasi.

\section{Hasil dan Pembahasan}

\section{Biografi K.H. Moenawar Chalil}

Moenawar Chalil lahir di Kendal, Jawa Tengah, pada tanggal 28 Februari 1908. Ia berasal dari keluarga kiyai yang terhormat, yang 
Pemikiran Politik K.H Moenawar Chalil (1908-1961)| Fajar Tahmid Aqimuddin, Fajriudin, Dina Marliana

anggotanya telah memantapkan diri sebagai pedagang dan hartawan yang sukses. Ia mengenyam pendidikan tradisional di tangan ayahnya, Muhammad Chalil, serta pamannya bernama Muhammad Salim, dan para kyai lainnya di Kendal,

Pada usianya menginjak tujuh belas tahun, K.H. Moenawar Chalil pernah terlibat dalam pergerakan nasionalis dan bergabung dengan pemberontakan pada pemerintah di Kendal. Pemeberontakan tersebut terkait dengan kegiatan Sarekat Islam (SI) di Solo. Hal itu dikarena Sarekat Islam (SI) menjadi dua kelompok, SI Putih yang diketuai oleh H.O.S Cokroaminoto dan SI Merah yang dipimpin oleh Semaun yang kemudian menjadi Partai Komunis Indonesia (PKI) dan memberontak melawan pemerintah Hindia Belanda pada tahun $1926^{2}$.

Perpecahan dalam Sarekat Islam terjadi pada tahun 1921 yang mulai terlihat saat menyelenggarakan kongres sebanyak dua kali. Kongres CSI (Central Sarekat Islam). Kongres pertama di selenggarakan pada tanggal 1-7 Maret 1921 di Yogyakarta yang lebih mengutamakan persatuan dan kesatuan dalam organisasi Sarekat Islam. Kemudian Diadakan kembali Kongres kedua pada tanggal 6-10 Oktober 1921 yang menetapkan suatu disiplin partai. Hal tersebut dikarenakan agar organisasi Sarekat Islam didalam anggotanya mampu terbebas dari golongan pemikiran komunis dengan tidak memasuki himpunan yang lain. Pada saat kongres kedua tersebut dilaksanakan, sebelumnya telah terjadi perdebatan antara CSI yang diwakili Haji Agus Salim dengan kader komunis yang diwakili oleh Semaun ${ }^{3}$. Karena kegagalan golongan komunis, Akibatnya Sarekat Islam Semarang menjadi Perserikatan Komunis India (PKI) ${ }^{4}$.

Meskipun beliau berpartisipasi dalam Sarekat Islam, beliau tetap berada di bawah kecurigaan dan pada akhirnya beliau pun ditangkap pada tahun 1926 Maka dari itu, beliau diputuskan untuk

\footnotetext{
${ }^{2}$ Moenawar Chalil, Kelengkapan Tarikh Nabi Muhammad, Jilid 2 (Jakarta: Gema Insaini Press, 2001), 296

${ }^{3}$ Yeti Setiawati dan Samsudin Samsudin, "Gerakan Politik Sarekat Islam di Jawa Tahun 1916-1921,” Hist. Madania J. Ilmu Sej. 4, no. 2 (2020): 368, doi:10.15575/hm.v4i2.9502

${ }^{4}$ Ahmad Mansyur Suryanegara, Api Sejarah, 1 ed. (Bandung: Suryadinasti, 2018), 415
} 
Pemikiran Politik K.H Moenawar Chalil (1908-1961)| Fajar Tahmid Aqimuddin, Fajriudin, Dina Marliana

dibuang menuju Irian Jaya oleh Wedono, Kendala. Di Irian Jaya tepatnya di Boven Digoel merupakan tempat para tokoh untuk para tawanan politik selama masa kolonial. Tetapi keputusan oleh Wedono dibatalkan oleh Muhammad Chalil dengan cara membujuknya melalui surat yang ia kirimkan, karena K.H. Moenawar Chalil ingin dikirim oleh ayahnya ke Arab Saudi 5 .

Pada tahun 1926, Akhirnya K.H Moenawar Chalil dikirimkan oleh ayahnya untuk mengeyam pendidikan di Arab Saudi sampai 1929 selama empat tahun. Selama beliau tinggal di Arab Saudi, beliau dipengaruhi oleh semangat Reformis Wahhabi yang kemudian memanifestasikan dirinya dalam beberapa tulisan dan kegiatan reformisnya sendiri. Selama tinggal di Arab Saudi pun beliau menyadari bahwa tren di Mesir dan daerah di sekitarnya selama beliau tinggal di Hijaz. Beliau sangat terkesan dan terpengaruh oleh pandangan modernis Muhammad Abduh, seperti hal yang terlihat dari sejumlah tulisan Abduh yang dia baca dan kutip dalam banyak karyanya ${ }^{6}$.

Pada tahun 1929, beliau kembali ke Indonesia. sekembali dari Arab Saudi beliau menjadi anggota aktif organisasi Muhammadiyah di Cabang Kendala. ${ }^{7}$ Beliau menjadi guru di al-Madrasah al-Wustha (sekolah menengah) dan menjadi ketua pusat Majlis Tabligh (Badan Dakwah) cabang Muhammadiyah di Kendal. Pada tahun 1930 K.H. Mas Mansur mengangkat K.H. Moenawar Chalil sebagai anggota Majlis Tarjih Pimpinan Pusat Muhammadiyah dua tahun setelah berdirinya, yakni pada tahun 1928 oleh K.H. Mas Masur ${ }^{8}$.

Pada Tahun 1933 beliau pindah ke Semarang untuk ditugaskan mengajar mata kuliah Dakwah di cabang Muhammadiyah dan beliau sempat menjadi ketua redaksi majalah Swara Islam pada tahun 1934

\footnotetext{
${ }^{5}$ Thohah Hamim, Paham Keagamaan Kaum Reformis (Yogyakarta: PT Tiara Wacana Yogya, 2000), 32

${ }^{6}$ Ahmad Choirul Rofiq, "Early Historiography of Sirah Nabawiyah In Indonesia: Study of Moenawar Chalil's Kelengkapan Tarikh Nabi Muhammad," Inst. Agama Islam Negeri Ponorogo 18 (2020): 24

7 (Chalil, 2001; 296)

${ }^{8}$ Rofiq, "Early Historiography of Sirah Nabawiyah In Indonesia: Study of Moenawar Chalil's Kelengkapan Tarikh Nabi Muhammad," 26
} 
Pemikiran Politik K.H Moenawar Chalil (1908-1961)| Fajar Tahmid Aqimuddin, Fajriudin, Dina Marliana

sampai $1935^{9}$. Beliau juga aktif menulis di majalah Swara Islam menggunakan bahasa Jawa agar mampu menjangkau masyarakat lebih besar sebagai sebuah bahasa kebanyakan di Indonesia ${ }^{10}$. Majalah ini didirikan dalam rangka menghidupkan kembali sunnah nabi dan memberantas bid'ah yang tidak beralasan.

Pada tahun 1941 beliau juga menjadi sekretaris Lajnah AhliAhli Hadits Indonesia yang pada saat itu diketuai oleh K.H. Ma'shum. Beliau menjadi sekertaris tersebut hingga kematiannya pada 23 Mei $1961^{11}$.

Ketika Jepang menduduki Indonesia pada tahun 1942, beliau terpaksa menghentikan kegiatannya untuk menjadi penulis dan beralih untuk terlibat kedalam urusan brokrasi. Beliau terpaksa menerima tawaran Jepang menjadi Kepala Departemen Agama Kabupaten Semarang. Maka dari sinilah K.H. Moenawar Chalil terlihat mau berkeja sama dengan para rezim namun dengan keinginan yang terpaksa. Selama menjadi Kepala Departemen Agama tersebut, beliau menjalankan urusan birokrasi hampir selama sepuluh tahun lamanya, akhirnya beliau mulai menyadari untuk tidak setuju pada kepemimpinan politik di Indonesia.

Ketika salah satu dokumen yang dikirimkan oleh pimpinan Tentara Islam Indonesia (TII) dan Darul Islam (DI) kepada K.H. Moenawar Chali yang ditemukan di Cirebon pada akhir tahun 1951 yang berisi tentang menjanjikannya untuk menjadi jabatan Gubernur di Jawa Tengah. Hal ini terlihat bahwa DI/TII ingin menguasai Indonesia maka bahwa beliau dituduh sebagai salah satu tokoh akan menghancurkan pemerintahan yang sah, akhirnya beliau dipenjarakan selama tujuh bulan sebelum Hari Raya Idul Fitri dan dibebaskan kembali pada tahun $1952{ }^{12}$ oleh pihak yang berwenang setelah dakwaan tersebut tidak terbukti memiliki dokumen pendukung lainnya.

\footnotetext{
${ }^{9}$ Dkk Herry Mohammad, Tokoh-Tokoh Islam Yang Berpengaruh Abad 20 (Jakarta: Gema Insaini Press, 2006), 125

${ }^{10}$ Thohah Hamim, Paham Keagamaan Kaum Reformis, 57

${ }^{11}$ Rofiq, "Early Historiography of Sirah Nabawiyah In Indonesia: Study of Moenawar Chalil's Kelengkapan Tarikh Nabi Muhammad," 25

${ }^{12}$ (Chalil, 2001:297)
} 
Pemikiran Politik K.H Moenawar Chalil (1908-1961)| Fajar Tahmid Aqimuddin, Fajriudin, Dina Marliana

Pada tahun 1951, beliau mengundurkan diri dari Departemen Agama pada usia 43 tahun tanpa diberikan dana pensiun ${ }^{13}$.

Setelah K.H. Moenawar Chalil mengundurkan diri dari pemerintah pada tahun 1951, beliau menemukan jalan untuk aspirasi politiknya yang bergabung ke dalam partai politik bernama Majelis Syura Muslimin Indonesia atau lebih dikenal Masyumi. Tak menunggu waktu lama, beliau diangkat menjadi pengurus Majelis Syura Pusat.

Pada tahun 1952 dibulan pertengahan Oktober, beliau menolak tawaran jabatan tinggi dari Soekarno di Jakarta dan ia juga menolak manjadi jabatan Menteri Agama yang pernah ditawarkan kepadanya oleh kabinet koalisi Masyumi dan Partai Nasional Indonesia (PNI) ${ }^{14}$. Alasan K.H. Moenawar Chalil menolak tawaran untuk menjadi jabatan tertinggi dan pegawai negeri oleh Soekarno ialah karena ingin melanjutkan kembali memfokuskan diri mengerahkan tenaga dan waktunya untuk menjadi penulis produktif yang pernah terhenti sejak $1941^{15}$.

Pada tahun 1957 K.H. Moeawar Chalil menjabat sebagai ketua Majelis Ulama Pengurus Pusat Persis di Bandung. beliau telah ikut keanggotaan Persis sejak awal pada tahun 1930-an, saat itu ia menjabat sebagai kolumnis reguler untuk majalahnya yakni Pembela Islam untuk yang berada di wilayah Kendal. Sejak saat itu beliau memiliki dua keanggotaan, diantaranya ialah sebagai anggota terpandang di Muhammadiyah dan kolumnis Persis.

Jabatan keagamaan lainnya yang pernah dijabat oleh beliau antara lain penasihat Pusat Pendidikan Islam di Solo dan juga menjadi anggota Panitia Pertimbangan Kesehatan dan Syara Departemen Kesehatan. Pada tahun 1958, sebuah jajak pendapat dilaksanakan oleh Himpunan Pengarang Islam Indonesia (Ikatan Penulis Muslim Indonesia) di Jakarta untuk menentukan peringkat penulis. Beliau ditempatkan berada di peringkat kelima. Beliau menyerupai dengan

\footnotetext{
${ }^{13}$ Rofiq, "Early Historiography of Sirah Nabawiyah In Indonesia: Study of Moenawar Chalil's Kelengkapan Tarikh Nabi Muhammad," 26

${ }^{14}$ Dkk Harun Nasution, Ensiklopedia Islam di Indonesia, Jilid 2 (Jakarta: Departemen Keagamaan R.I, 1988), 630

${ }^{15}$ Chalil, Kelengkapan Tarikh Nabi Muhammad, 297-98
} 
Pemikiran Politik K.H Moenawar Chalil (1908-1961)| Fajar Tahmid Aqimuddin, Fajriudin, Dina Marliana

para penulis intelektual produktif seperti halnya Hasbi Ash-Shiddiqey dan A. Hassan ${ }^{16}$.

K.H. Moenawar Chalil wafat pada 23 Mei 1961 dalam usia 53 tahun di Kampung Kulitan 313, Semarang. Beliau terjangkit kanker paru-paru dan tumor otak selama kurang lebih dua bulan.

\section{Nasionalisme Menurut K.H. Moenawar Chalil}

Pemikiran politik yang pernah beliau sampaikan yang sama dengan fatwa Persis yang berhubungan dengan adanya nasionalisme secara umum, kemudian dasar-dasar nilai filosofis kenegaraan dan juga terdapatnya pengkafiran dominan politik yang berlawanan dengan tujuan politik umat Muslim. Salah satu karyanya yang pernah beliau kritik ialah tentang penolakan kaum nasionalisme sekuler terhadap unsur-unsur yang ada dalam Islam yang secara historis terdapat di dalam nasionalisme Indonesia. Menurut K.H. Moenawar Chalil, bangunan naisonalisme Indoensia yang besar hanya terdapat di dalam Islam, karena Islam pun mengajarkan nasionalisme kepada manusia.

Lebih lanjut K.H. Moenawar Chalil menjelaskan bahwa upaya kaum nasionalisme sekuler di Indonesia untuk mengadopsi model pemikiran nasionalisme sekuler Turki adalah sesat. Dalam nasionalisme Turki, K.H. Moenawar Chalil menjelaskan bahwa agama Islam menjalankan peranan-peranan penting dalam menyatukan seluruh tingkatan masyarakat di Turki, sebuah penyatuan yang menjadi penentu kejayaan Negara Turki dalam sebuah Perang Kemerdekaan dan upayaupaya mereka untuk memukul mundur Yunani dari tanah Turki ${ }^{17}$.

Sebagai seorang ulama yang berusaha untuk menerapkan syari'ah sebagai hukum yang baik dan benar, beliau mempercayai bahwa Islam merupakan sebuah sistem politik yang sempurna dan ideal yang telah membuang jauh akar sejarah kaum nasionalis sekuler. Lebih lanjut beliau menyalahakan mereka para nasionalis sekuler mengabaikan Islam dalam UUD 1945 yang membangun fondasi Republik Indonesia.

\footnotetext{
${ }^{16}$ Thohah Hamim, Paham Keagamaan Kaum Reformis, 56

${ }^{17}$ Thohah Hamim, Paham Keagamaan Kaum Reformis, 49
} 
Pemikiran Politik K.H Moenawar Chalil (1908-1961)| Fajar Tahmid Aqimuddin, Fajriudin, Dina Marliana

K.H. Moenawar Chalil mengkritik mereka yang mengakumengaku hanya menjadi pengikut islam tetapi secara pergerakan politik tidak terlibat dalam mengimplementasikan upaya mengedepankan sistem Islam sebagai satu-satunya sistem kekuasaan di Indonesia. Karena itu beliau lebih mempertegas dan memperjelas lagi bahwa yang harus menjadi satu-satunya ideologi yang baik dan benar bagi negara adalah Islam. Beliau berharap bahwa sistem Islam akan diuntungkan.

\section{Fungsi Ulama Dalam Kenegaraan}

K.H. Moenawar Chalil sebagai salah seorang ulama tentunya sangat menyadari bahwa para ulama mempunyai otoritas aqidah dan moral di antara mayoritas umat Islam yang ada di Indonesia. Beliau menganggap seperti itu karena para ulama merupakan pusat inti untuk membuka luas masalah-masalah sosial dan politik dengan berupaya mengatasinya. Seorang ulama memiliki tanggung jawab yang sangat besar untuk melakukan suatu persoalan dengan cara bijaksana dan hikmah yang baik. Seorang ulama dituntut untuk harus bekerja kepada bangsa dan negara bagi persatuan dan kesatuan umat karena itulah mereka sebagai penyambung undang-undang atau pesan dari Allah yang tertuang dalam sejarah Islam kepada para generasi sesudah para $\mathrm{Nabi}^{18}$.

Meskipun peran ulama ialah sebagai penyambung pesan dari Allah dan merupakan pemegang teguh kebenaran yang murni untuk dijaga, K.H. Moenawar Chalil memutuskan bahwa para ulama semestinya bertanggung jawab untuk memberi artikulasi yang tegas kepada umat Islam. Beliau lebih lanjut lagi menjelaskan bahwa umat Islam kerap kali mengutip kata-kata para ulama yang pernah mereka tangkap dengan nalarnya, sementara itu pada waktu yang pun sama umat Islam tidak begitu mendengarkan apa kata-kata yang keluar dari para pejabat pemerintah mengenai permasalahan yang sama.

Dalam karyanya yang pernah beliau tuliskan, K.H. Moenawar Chalil sangat mengancam para ulama yang telah menyalahgunakan kepercayaan masyarakat Islam Indonesia dan mereka yang melakukan

\footnotetext{
${ }^{18}$ Moenawar Chalil, Funksi Ulama Dalam Masjarakat Dan Negara (Djakarta: Bulan Bintang, 1957), 27-28
} 
Pemikiran Politik K.H Moenawar Chalil (1908-1961)| Fajar Tahmid Aqimuddin, Fajriudin, Dina Marliana

manipulasi demi kedudukan dan suatu materi untuk diri mereka. Kemudian beliau menjelaskan, jika peran ulama dalam kenegaraan sudah seperti itu maka mereka sama halnya telah meninggalkan masyarakat dalam keadaan yang terpecah belah oleh kebencian ataupun diskriminasi akibat perbedaan, terutama di negara Indonesia yang memiliki banyak keberagaman agama, suku, dan ras.. Beliau menyatakan dengan tegas bahwa seorang ulama semacam itu merupakan ulama yang curang atau tidak bermoral. Termasuk seorang ulama yang curang, biasanya merasa takut berhadapan untuk membicarakan kebenaran dan hanya mengabdi dan patuh kepada penguasa yang secara sistem melakukan penindasan ${ }^{19}$.

K.H Moenawar Chalil pun menempatkan ulama sebagai satusatunya wakil seluruh umat yang menghubungkan ijma' di dalam negara semacam lembaga legislatif. Dasar pijakan konsep beliau melalui pendirian majelis tunggal yakni untuk merangkul semua ulama tantang ijma, karena para ulama merupakan satu-satunya pembuat hukum $^{20}$. Dengan adanya perkembangan jaman, beliau berpendapat tantang ijma ulama mengenai berbagai persoalan yang baru yang menurutnya berbeda dengan ijma para sahabat nabi dikarenakan kesempurnaanya menjadi suatu sumber hukum.

Menurut K.H. Moenawar Chalil, uli al-amr sebagai majelis syura yang mewakili masyarakat muslim, tidak hanya melindungi kepentingan agama, melainkan seharusnya memutuskan permasalahanpermasalahan dunia yang ada didalam masyarakat bernegara. Beliau menunjukan bahwa Abu Bakar Ash-Shiddiq pernah untuk memerintahkan kepada para pemimpin dan para ulama agar bermusyawarah dalam suatu urusan ${ }^{21}$. Kemudian juga pernah dilakukan oleh Umar bin Khattab terhadap permasalahan yang dasarnya belum ditemukan di dalam Al-Quran maupun hadits Nabi. Beliau juga menyatakan bahwa musyawarah yang pernah dilakukan oleh Umar dan Abu Bakar merupakan keputusan dan rumusan telah final yang

\footnotetext{
${ }^{19}$ Chalil, Funksi Ulama Dalam Masjarakat Dan Negara, 23

${ }^{20}$ Thohah Hamim, Paham Keagamaan Kaum Reformis, 202

${ }^{21}$ Moenawar Chalil, Adakah Ulil Amri di Indonesia (Solo: Siti Sjamsijah, 1958), 26
} 
Pemikiran Politik K.H Moenawar Chalil (1908-1961)| Fajar Tahmid Aqimuddin, Fajriudin, Dina Marliana

dilaksanakan oleh pemimpin-pemimpin yang tengah berupaya untuk menemukan jalan keluarnya ${ }^{22}$.

\section{Peran Wanita dalam Politik}

Dalam karyanya yang berjudul Nilai Wanita, terdapat dua poin yang penulis analisis terkait pemikiran politik K.H. Moenawar Chali. Poin yang pertama beliau menilai wanita dalam pandangan politiknya yang memiliki peran penting untuk berusaha mencapai kesempurnaan negara dengan memberikan aspirasi suara mereka.

Beliau menceritakan bagaimana Umar bin Khattab memutuskan suatu perkara ketika ia menjabat sebagai Khalifah yang kedua, yakni perkara maskawin bagi seorang laki-laki yang akan diberikan kepada perempuan menjadi dinaikan sampai lebih dari 400 dirham. Diceritakan bahwa Umar memutuskan hal tersebut karena pada saat masa jabatan Khalifahnya rakyat sedang dalam keadaan makmur dan sejahtera, Namun tetap saja Umar sangat mengkhawatirkan jika dikemudian hari kedepannya rakyat menjadi dalam kondisi yang tidak makmur. Karena keputusan itulah, masyarakat banyak yang tidak menyetujui jika maskawin yang diberikan kepada perempuan dilebihkan sebesar 400 dirham. Kemudian datanglah dari golongan Quraisy seorang wanita menghadap kepada Umar dan menentang kebijakan tersebut. Wanita dari bangsa Quraisy itu menyampaikan sepengal ayat yang isinya "Dan jika kamu telah beri sepikul (Maskawin) pada salah seorang perempuan, maka janganlah kamu ambil kembali daripadanya sedikitpun" (4:20)

Setelah mendengar ayat tersebut, Umar meminta ampunan kepada Allah karena keputusan yang kurang baik kepada rakyatnya dan mengakui kesalahannya lalu membenarkan apa yang diucapkan oleh wanita Quraisy tersebut. Kemudian Umar segera membenarkan kebijakan perkara maskawin dengan mencabut keputusannya, lalu menggantikannya dengan yang telah dikemukakan oleh salah seorang wanita Quraisy.

\footnotetext{
${ }^{22}$ Moenawar Chalil, Biography Empat Serangkai (Jakarta: Bulan Bintang, 1992), 215
} 
Pemikiran Politik K.H Moenawar Chalil (1908-1961)| Fajar Tahmid Aqimuddin, Fajriudin, Dina Marliana

K.H. Moenawar Chalil menceritakan riwayat tersebut untuk menunjukan bahwa nilai wanita pun memiliki keberanian untuk meluruskan perkara meskipun dihadapan Khalifah yang terkenal adil dan cakap. Dalam hal inilah wanita pun berhak berperan untuk menyampaikan asprasi rakyatnya dengan kebenaran jika kepentingan umum dan kepentingan pemerintahannya tidak terasa indah diterapkan.

Poin yang kedua ialah bagaimana nilai wanita memposisikan diri sebagai pemimpin dalam pemerintahannya dalam memutuskan urusan yang beliau merefleksikan dalam kisah sejarah Ratu Balqis di Negeri Saba.

Beliau meceritakan tentang Ratu Balqis yang sedang menimbang tawaran dari Raja Sulaiman yang dikirim melalui sepucuk surat. Maka Ratu Balqis menyelenggarakan sebuah sidang parlemen kepada para pemuka untuk mendiskusikan tawaran tersebut. Ia meminta kepada para kepala umatnya untuk memberikannya fatwa terhadap urusannya. Kemudian ia pun menyatkan untuk tidak akan mengambil keputusan sendiri kecuali para pemuka yang menghadiri sidang telah memberikan pendapatnya. Namun mereka malah tidak memikirkannya dan menyerahkan keputusannya secara tunggal yang diserahkan kembali kepada Ratu. Ia pun berkata dan termaktub dalam Al-Quran "Sesungguhnya para raja itu apabila datang masuk ke suatu negara, tentu mereka merusaknya dan menjadikan penduduknya yang tadinya mulia pada kehinaan dan dimikianlah mereka bertaubat" (AnNaml : 32)

Dalam kisah tersebut K.H. Moenwar Chalil mengambil dua makna. Makna yang pertama seorang wanita yang cakap mengatur dalam urusan tata negara, terlihat jelas bahwa dalam segala urusan yang berkenaan dengan pemerintahannya didiskusian terlebih dulu di dalam sidang parlemen bersama pihak-pihak tertentu dan tidak mengambil keputusan sendiri. Dalam pandangannya, beliau mencoba untuk meyakinkan agar kaum muslimin terutama di Indonesia dapat melakukannya seperti demikian juga dalam memimpin negara dan mengatur politiknya dengan benar.

Makna yang kedua terlihat bahwa K.H. Moenawar Chalil yang mengutip perkataan Ratu Balqis yang termaktub dalam Al-Quran, 
Pemikiran Politik K.H Moenawar Chalil (1908-1961)| Fajar Tahmid Aqimuddin, Fajriudin, Dina Marliana

ternyata Ratu Balqis mengetahui jika raja-raja memasuki suatu negara orang lain, maka pasti mereka pun akan membinasakan Negara tersebut. Negara yang tadinya mulia raya menjadi dijajah dan dihinadina. Beliau menambahkan argumennya lagi bahwa jika Negara penjajah itu terlebih lagi terhadap bangsa yang berlainan agama yang bukan dari kaum muslimin akan dihina. Bahkan tidak hanya terhadap umat Islam, tetapi agama Islamnya pun akan dihina juga ${ }^{23}$.

Dengan riwayat yang itu dapatlah diambil ibarat, bahwa sekalipun golongan wanita harus pandai dan cakap pula dalam urusan ketata-negaraan atau politik.

\section{Khilafah Menurut K.H. Moenawar Chalil}

Beliau menjelaskan definisi kata dari Khilafah yang mengutip dari beberapa tokoh Ulama terkemuka. Sebagai salah satu contoh, beliau mengutip perkataan Ibnu Khaldun yang mengatakan bahwa Khalifah itu beban bagi sepanjang pandangan syara' untuk kemaslahatan ukhrawi dan duniawi yang akan kembali kepada-Nya, karena hal ihwal itu semuanya menurut syara' dapat diibaratkan untuk kemashlahatan akhirat. Maka dari itu dalam hakikatnya Khilafah itu ialah pengganti pemimpin syariat (Nabi) dalam memelihara agama dan siasat dunia ${ }^{24}$.

Ta'rif atau definis Khalifah menurut para ulama yang beliau ambil secara keseluruhan memiliki makna yang sama, yaitu merupakan pimpinan atau pemerintahan mengenai urusan keagamaan dan dunia setelah wafatnya Rasulullah sebagai penggantinya.

Eksistensi Khalifah dalam Islam menurut K.H. Moenawar Chalil mengandung kepentingan yang besar bagi Islam dan kaum muslimin. Para ulama Islam sejak dari jaman dulu telah membahas hukumnya mendirikan khalifah dan mengangkat khalifah. Dalam pandangannya, hukum mendirikan Khilafah merupakan kewajiban bagi segenap umat Islam. Kewajiban mendirikan khilafah seperti melaksanakan kewajiban kifayah, misalnya Jihad dan qadha. Yakni apabila seseorang yang memiliki keahlian dalam suatu urusan lalu telah

\footnotetext{
${ }^{23}$ Moenawar Chalil, Nilai Wanita (Semarang: Ramadhani, 1990), 77

${ }^{24}$ Ibnu Khaldun, Muqaddimah Ibn Khaldun (Beirut: Dar al-Fikr, 1988), 239
} 
Pemikiran Politik K.H Moenawar Chalil (1908-1961)| Fajar Tahmid Aqimuddin, Fajriudin, Dina Marliana

mendirikannya, maka gugurlah kewajiban segenap umat Islam. Kemudian apabila tidak ada seorang pun yang mendirikannya, beliau menegaskan bahwa durhakalah segenap umat Islam, Sehingga berdirilah suatu urusan khilafah itu dengan seksama dan harus didirikan oleh orang yang mempunyai keahlian tentang hal itu ${ }^{25}$.

Beliau mengambil sebagian ulama yang berpendapat bahwa kedurhakaan itu akan ditimpakan kepada dua golongan umat Islam, yakni golongan orang ahli dalam berpikir yang memiliki intelektual untuk sanggup memilih pemimipin, sehingga mereka memilih dan mengangkat seorang khalifah. Lalu golongan yang kedua ialah golongan orang yang diantara mereka itu memiliki cukup beberapa syarat menjadi kekhilafahan, hingga dapat memilih salah seorang dari mereka itu untuk menjadi Khalifah.

Tetapi pendapat yang benar menurut K.H. Moenawar Chalil, kedurhakaan itu akan ditimpakan kepada seluruh umat Islam, karena bagi seluruh umat Islam itu telah diperintahkan untuk mendirikan khalifah. Demikianlah, maka jumhur ulama telah menghukumkan wajib bagi segenap umat Islam sepanjang masa untuk mendirikan khilafah dan memilih atau menganggakat khilafah.

Mengenai kewajiban mengangkat Khalifah, beliau menjelasakan sebab-sebab mengapa harus diberlakukannya untuk mendirikan khalifah. Pertama, diasarkan atas Ijma atau kesepakatan yang pernah terjadi pada saat Rasulullah wafat. Ketika itu jenazah beliau belum diurus lebih lanjut untuk dimakamkan, tetapi para sahabat besegera untuk melakukan permusyawaratan dan kemudian memba'iat Abu Bakar menjadi Khalifah. Menurut beliau, jika mengangkat Khilafah tidak wajib, seharusnya para sahabat tidak bersegera untuk melakukan hal itu. Dasar yang kedua beliau menuturkan kembali bahwa untuk memberlakukan adanya hukum-hukum seperti hudud, qishas dan lain-lain, kewajiban-kewajiban tersebut tidak akan dapat sempurna kecuali mesti dengan adanya kekuasaan Khalifah, maka suatu hukum yang menjadi syarat bagi kesempurnaan suatu kewajiban itu menjadi wajib hukumnya. Lalu dasar yang ketiga, bahwa yang

\footnotetext{
${ }^{25}$ Moenawar Chalil, Khalifah (Kepala Negara) Sepanjang Pimpinan Al-Quran dan Sunnah, 2 ed. (Solo: C.V. Ramadhani, 1984), 37
} 
Pemikiran Politik K.H Moenawar Chalil (1908-1961)| Fajar Tahmid Aqimuddin, Fajriudin, Dina Marliana

menjadi kewajiban agama pun ialah menarik kemashlahatan dan menolak kemeralatan sebagaimana Khalifah pun berkewajiban demikian. Demikian dengan tiga dasar atas di berdirikannya Khilafah itu merupakan suatu kewajiban sepanjang pimpinan syara' yang wajib dikerjakan oleh seluruh umat Islam ${ }^{26}$.

\section{Simpulan}

K.H. Moenawar Chalil berpandangan politik dalam sebuah negara islam yang ideal. Bagaimana ajaran Islam bisa ddiwujudkan tanpa ada halangan apapun. Pandangan beliau sejalur dengan Majelis Syuro Muslimin Indonesia yang pada saat jamannya telah berusaha keras untuk mencapainya, meskipun pada akhirnya gagal dengan dikeluarkannya Dekrit Presden pada tanggal 5 Juli 1949 yang dimana merupakan dasar negara RI adalah Pancasila dan UUD 1945.

Segala jerih usaha yang pernah dilakukan oleh K.H. Moenawar Chalil untuk mewujudkan Negara negara Islam ideal itu adalah dengan diadakannya persatuan para ualama. Dalam pandangannya, jika sebuah negara Islam ditegakkan, maka para ulama akan tampil mendapat peran sebagai penasehat atau pembantu penguasa. pemikiran politik dan pembaruan K.H. Moenawar Chalil jelas tampak telah dipengaruhi oleh para tokoh pemikir dari Timur Tengah yang berupaya menegakkan ajaran Islam dalam seluruh kehidupan. Kesadaran politik beliau memancarkan semangat aktivisme yang didapatkan melalui interaksi dan diskusi dalam ranah intelektualitasnya dengan kaum pembaharuan di Timur Tengah, yang ingin mewujudkan lebih sempurna ajaran-ajaran Islam di atas konsep-konsep ideologi yang di buat oleh manusia.

\footnotetext{
${ }^{26}$ Chalil, Khalifah (Kepala Negara) Sepanjang Pimpinan Al-Quran dan Sunnah, 3839
} 
Pemikiran Politik K.H Moenawar Chalil (1908-1961)| Fajar Tahmid Aqimuddin, Fajriudin, Dina Marliana

\section{Daftar Sumber}

Chalil, Moenawar. Adakah Ulil Amri di Indonesia. Solo: Siti Sjamsijah, 1958.

—. Biography Empat Serangkai. Jakarta: Bulan Bintang, 1992.

- Funksi Ulama Dalam Masjarakat Dan Negara. Djakarta:

Bulan Bintang, 1957.

- Kelengkapan Tarikh Nabi Muhammad. Jilid 2. Jakarta: Gema Insaini Press, 2001.

- Khalifah (Kepala Negara) Sepanjang Pimpinan Al-Quran dan Sunnah. 2 ed. Solo: C.V. Ramadhani, 1984.

_. Nilai Wanita. Semarang: Ramadhani, 1990.

Harun Nasution, Dkk. Ensiklopedia Islam di Indonesia. Jilid 2. Jakarta: Departemen Keagamaan R.I, 1988.

Herry Mohammad, Dkk. Tokoh-Tokoh Islam Yang Berpengaruh Abad 20. Jakarta: Gema Insaini Press, 2006.

Ibnu Khaldun. Muqaddimah Ibn Khaldun. Beirut: Dar al-Fikr, 1988.

Khikmawati, Ida. "Telaah Metodelogis Pemikiran K.H. Moenawar Chalil Tentang Slogan Kembali Kepada Al-Qur'an (Studi Atas Buku Kembali Kepada Al-Qur'an dan As-Sunnah)." UIN Sunan Kalijaga, 2020.

Rofiq, Ahmad Choirul. "Early Historiography of Sirah Nabawiyah In Indonesia: Study of Moenawar Chalil's Kelengkapan Tarikh Nabi Muhammad." Institut Agama Islam Negeri Ponorogo 18 (2020): 19-38.

Setiawati, Yeti, dan Samsudin Samsudin. "Gerakan Politik Sarekat Islam di Jawa Tahun 1916-1921." Historia Madania: Jurnal Ilmu Sejarah 4, no. 2 (2020): 355-72. doi:10.15575/hm.v4i2.9502. 
Pemikiran Politik K.H Moenawar Chalil (1908-1961)| Fajar Tahmid Aqimuddin, Fajriudin, Dina Marliana

Suryanegara, Ahmad Mansyur. Api Sejarah. Jilid 1. Bandung:

Suryadinasti, 2018.

Thohah Hamim. Paham Keagamaan Kaum Reformis. Yogyakarta: PT Tiara Wacana Yogya, 2000. 